\title{
Sunflower Oil Functional Properties for Specialty Food
}

\author{
Rosa Franco*, Luca Iseppi and Mario Taverna \\ University of Udine, Italy
}

Submission: December 4, 2017; Published: February 23, 2018

*Corresponding author: Franco Rosa, University: University of Udine, Via delle scienze 206, Italy, Tel: 0432-558314; Cell: 3204365951;

Email: rosa@uniud.it

Keywords: Sunflower; Oil; Food; Nutraceutic; Vitamins; Tocopherols

\section{Introduction}

The sunflower seed oil is an agricultural raw commodity mainly used for cooking and sold at a price not different to other seed oils and well below the olive oil. Millions dollars have been spent in USA to advertise some commodity goods to increase the consumer loyalty. Medical knowledge and advance in biotechnologies and genomics allows creating new sunflower varieties by changing the mix of fat components to challenge the consumers' needs. The most profitable market segments of sunflower oil are functional foods for human consumption and oil for the industry

The word nutraceutic derives from combining elements of the words 'nutrients' and 'pharmaceuticals' and encompass very different food products with healthy effects. The French Nutraceutical School is based on the principle of nutritional synergy: "The wider the spectrum of nutrients in natural composition, the better is the assimilation and the efficacy. Functional foods have also been defined products that have been modified or enriched with naturally occurring substances with specific physiologically preventative and/ or health-enhancing effects [1]. Functional claim means that a food procures positive effects on one or more specific functions of the human body that goes beyond the normal nutritional effects so that there is an improvement in the state of health, well-being and/or possible demonstrated reduction of the risk of illness (health claim). Hence the functional foods have optimal compositions of active healthy component as minerals, vitamins, fatty acids or dietary fiber. This group embeds foods with added biologically active attributes such as ingredients of vegetable, antioxidants and probiotics with live cultures added having beneficial effects on human health.
Functional Food has been Classified in Different Categories here Listed

I. Non-altered products: Foods naturally containing increased content of nutrients or components.

II. Fortified products: Increasing the content of existing nutrients or components.

III. Enriched products: Adding new nutrients or components not normally found in nature.

IV. Altered products: Replacing existing components with beneficial components.

V. Enhanced commodities: Changing raw commodities to alter nutrient composition;

The proposed sunflower oil to be modified is included in the $2^{\text {nd }}$ group containing increased quantity of long fatty acid chain omega-3 DHA/EPA to reduce risk of cardiovascular disease.

The Basic Difference Between Nutraceutical and Functional Food

The nutraceutical refers to the single component of a food having therapeutic properties; the functional identifies foods with systemic action due to many components that as a whole interact together and procure benefits for the human metabolism, health and well-being. In the literature functional foods are considered the probiotics and prebiotics. Probiotics are live microbial food ingredients that have a beneficial effect on human health, traditionally found in fermented dairy products and vegetable oils with polyunsaturated fatty acids (PUFAs) (which include the omega- 3 and omega- 6 fatty acids), phytochemicals also play an important role as healthy 
dietary bioactive compounds. A balanced PUFA composition influences diverse aspects of immunity and metabolism. Moreover, interactions between PUFAs and components of the gut microbiota may also influence their biological roles. Phytochemicals (bioactive non-nutrient plant compounds), have raised interest in human nutrition because of their potential effects as antioxidants, anti-estrogenics, antiinflammatory, immunomodulatory, and anti-carcinogenic. Gut microbiota can, for example, transform and influence the bioavailability and the effects of polyphenols. Phytochemicals and metabolic products may also inhibit pathogenic bacteria and stimulate the growth of beneficial bacteria, exerting prebiotic-like effects. Interactions between functional food components, such as prebiotics, probiotics, phytochemicals, and intestinal microbiota, have consequences on human health [2]. The legislation concerning the ingredients allows some changes from one country to another in terms of dosage, origin and source of raw materials, treatments or processes to which they may or may not be subjected, The United Nations Organizations FAO/WHO Codex Alimentarius, the Council of Europe and the national regulatory bodies are setting out codes of conduct for manufacturers to put on the packaging only claims with scientifically proven healthy benefits. European labeling legislation prohibits the attribution to any food of the property of preventing, treating a human illness or referring to such properties. In the absence of a clear directive on this subject, the Member States of the European Union have applied various interpretations of the existing labeling legislation. For instance, the use of fatty acids is also allowed by many EU members but, while in Belgium their use must always be followed by a notification in regard, Denmark and Finland permit their use only if naturally occurring and in France they can be added only to dietetic foods. European community legislation must however overcome these inconsistencies [3]. The commercial interest of these functional foods is they have reached the grocery shelf. The demand for functional foods in Europe is steadily growing: according with the Food Safety Authority (EFSA), the high content of linoleic acid, essential fatty acids and vitamin E contained in sunflower oil makes this oil an ideal food for a healthy diet. The consumers informed about the healthy benefits are starting to prefer the sunflower oil to satisfy multiple needs: frying, dressing, functional. Over the past 20 years, breeders have made significant progress in creating sunflowers hybrid with different compositions of fatty acid especially the unsaturated ones: oleic (C 18:1, 16-19\%) and linoleic (C 18:2, 68-72\% LA) ones. Other oils: Palmitic (C 16:0, $6 \%$ ) and stearic (C 18:0,5\%) and minor amounts of myristic (C 14:0), myristoleic (C 14:1), palmitoleic (C 16:1), arachidic (C 20:0), behenic (C 22:0). Using DMS (dimethyl sulfate), the most important mutation induced is the high oleic acid (80-90\%) with implemented oxidation stability. The existence of mutant genes for increased levels of individual fatty acids and genes for different tocopherols suggest a rapid development of sunflower hybrids with appreciated oil quality. While sunflower breeders work on developing hybrid lines with different oil composition, medical scientists and nutritionists are searching to establish a functional correlation between oil composition and human health. The natural sunflower oil varieties contain a very high percentage of saturated fatty acids and minor quantities of unsaturated ones, some of these are essentials because the human organism has not the enzymes for their synthesis. The first essential polyunsaturated fatty acid is the linoleic acid belonging to the n-6 family (LA 18-2 n-6) up to 75\%) and isomers, the conjugated linoleic acid (CLA) with the same chemical composition but different spatial configuration of atoms [4-6] (Figure 1-2).

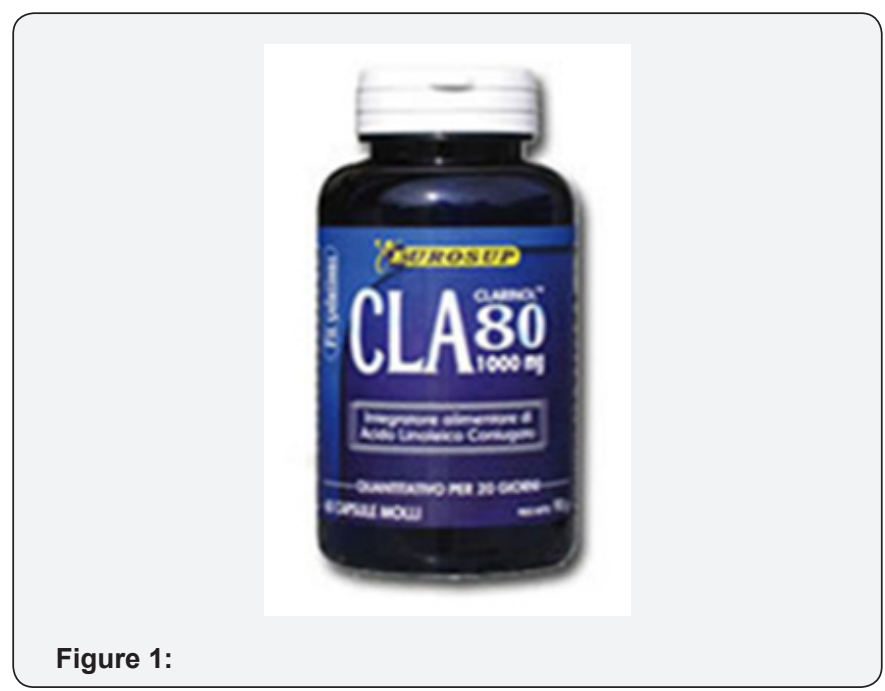

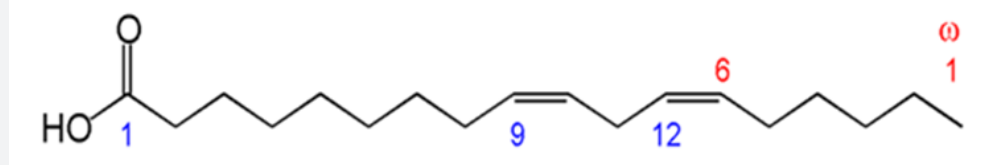

CLA is conjugated linoleic acid with a carbon chain of 18 atoms and 16 possible isomers; in nature are common the $18-2$ respectively the 9 cis-11 trans and 10 cis -12 trans

Figure 2: The CLA chain with bouble bonds in position 1, 9 and 12. 
Clinical studies suggest the main function of CLA is antithrombotic and immune-modulating and contribute to the formation of lean mass of muscles. The second essential polyunsaturated fatty acid is the $\alpha$-linolenic acid the omega 3 precursor, belonging to the n-3 family (ALA 18:3n-3). The human organism synthesizes albeit with a modest efficacy the ALA, the precursor of EPA (eicosapentaenoic acid) and DHA (docosahexaenoic acid), important especially for their functions anti-inflammatory, hypo-triglyceride, hypotensive and "fluidizing blood", which makes them a real help for the prevention and treatment of cardiovascular disease. However, due to the limited capacity to synthesize EPA and DHA from alpha linolenic acid, the healthy benefits deriving from sunflower oil are much lower in content than those obtained with consumption fish oil or others rich supplements in EPA and DHA. Here following is reported the scheme of the DHA and DPA formation from their precursors La and ALNA (Figure $3)$.

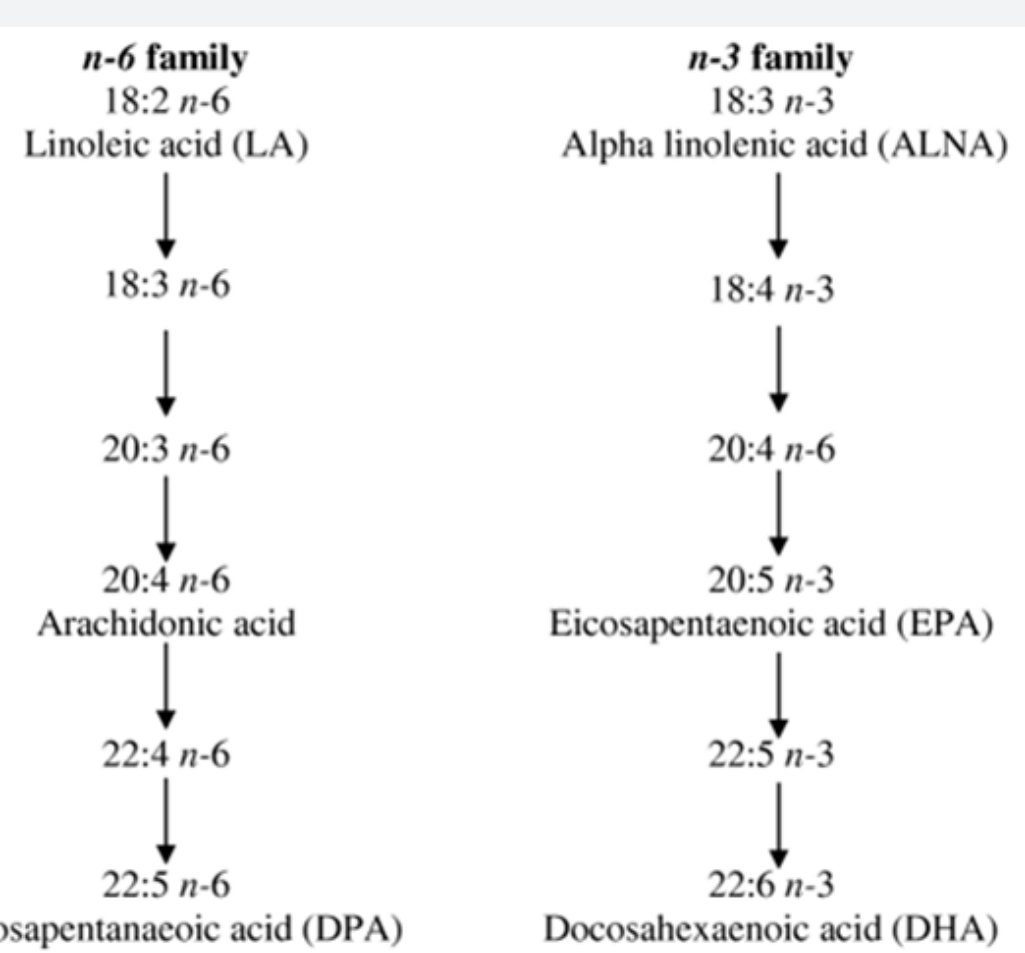

Figure 3: PUFA: LA and ALNA precursors of $\Omega 6$ and $\Omega 3$.

Polyunsaturated fatty acids can easily spoil, and then these types of oils should be stored in a refrigerator in waterproof containers, built with dark material to avoid the oxidation effect of the light, frequently treated with hydrogenation to reduce the double bonds. The sunflower oil composition varies according with the cultivar, environmental conditions, harvesting and processing. The fatty acid composition of sunflower seed oil varies on climate: cooler climates favor higher amounts of the n- 6 polyunsaturated fatty acid (PUFA) linoleic acid (an essential fatty acid, EFA); warmer climates, favor the MUFA oleic acid accumulation. The fatty acids have different properties and different health effects, and then it is needed to achieve a greater stabilization of the organoleptic composition for longer conservation. In recent time, the sunflower oil, perceived as inferior quality compared to olive oil, has livened up with the introduction of the higholeic varieties and improvement of the PUFA oil composition; It is currently estimated that the market share of sunflower seed oil is $42 \%$, followed by oil of various seeds, corn, peanut and soybean. Today, in Western diets, the combination of unsaturated fatty acids $\Omega-6 / \Omega-3$ is on the ranges $\approx 20-30: 1$ while the recommended optimal ratio is $10: 1$ from clinical research evidence. The unbalanced relationship $\Omega-6$ and $\Omega-3$ raises some medical concerns for people with obesity or high LDA cholesterol. The sunflower oil consumption in excess, without intentionally increasing the intake of omega-3, can cause an imbalance of unsaturated fatty acids that could induce healthy problems. The medical guidelines recommend a range from $450 \mathrm{mg} /$ day recommended by the UK Food Standards Agency, to $500 \mathrm{mg} /$ day recommended by the International Society for the Study of Fatty Acids and Lipids (ISSFAL), to $650 \mathrm{mg} /$ day of combined EPA and DHA recommended by expert groups from Australia, who indicate that DHA should represent a minimum of $220 \mathrm{mg}$. This means that DPA should be 4.5-6gr/day. Epidemiological studies indicate that higher amount of fatty acids $\Omega-6$ could cause a pro-thrombotic and 
pro-aggregate physiological state in some subjects, due to increased blood viscosity, vasospasm, and vasoconstriction with decreases the bleeding time. $\Omega-3$ has anti-inflammatory, antithrombotic, anti-arrhythmic, and hypoglycemic and vasodilating properties, secondary prevention of coronary artery disease, hypertension, type 2 diabetes, and in some patients with renal disease, rheumatoid arthritis, ulcerative colitis, Crohn's disease, and chronic obstructive bronchopneumopathy.

\section{Vitamins and Tocopherols}

The sunflower oil contains also significant amount of liposoluble vitamin $\mathrm{E}$ that is part of chemical compounds called tocopherols. There are several types of tocopherols in nature, the alpha-tocopherol is the most powerful form of vitamin $\mathrm{E}$ and has a high biological and nutritional value. The oxidation of fat generates the free radical soluble molecules that having an electron in the middle are very unstable, extremely reactive and can cause extensive damage to the body, from cancer to thrombosis, to DNA damage. Vitamin E has a major role as an antioxidant in the prevention of oxidation of polyunsaturated fatty acids (lipid peroxidation). Vitamin $\mathrm{E}$ is a potent immune stimulant, it acts in the prevention and treatment of heart disease such as coronary thrombosis and heart attack, in which the vessels are blocked by blood clots and part of the heart is deprived of its blood supply, Contrasts the oxidation of substances in the body and protects other substances from oxidation by supporting the attack of lipids or other membrane components. With these premises the research will be dedicated to the sunflower oil and modification with genetic/ omic technologies to achieve better functional properties [69].

\section{Conclusion}

This research topic has many implications for the health of the population and costs of the health system. The change the sunflower oil composition is also an important market target because the oil will change the category from commodity to specialty functional products targeted to new market segments. To afford this problem we have examined the main functional ingredients of the sunflower oil: fatty acid and vitamins and we have examined the possibility to achieve optimal combination targets: natural combination (the best in longer time) or the enrichment (the most feasible in shorter time). Options to increase MUFA and PUFA in optimal combination are a natural grow th with a genetic program that will require some years to be completed. This is the best option according with the definition of functional food that describes the systemic and synergic action of the all ingredients present in the oil composition to achieve the healthy benefit. A temporary option is the blending different types of vegetable oils to improve their nutritional profile, by increasing the omega-3 fatty acids, the most deficient fatty acid in sunflower oil in Western diets.

\section{References}

1. Poulsen J (2002) 'Danish consumers' attitudes towards functional foods" report 2002: University of Connecticut.

2. Cencic A, Chingwaru W (2010) "The Role of Functional Foods, Nutraceuticals, and Food Supplements in Intestinal Health". Nutrients 2(6): 611-625.

3. Geiser S (1999) “Marketing functional foods in Europe - Health Product Information", Vita foods International Conference, Aprile, Geneve , Switzerland, pp. 13-15.

4. Becker MH, Maiman LA, Kirscht JP, Haefner DP, Drachman RH (1977) "The health belief model and prediction of dietary compliance: a field experiment". J Health Soc Behav 18(4): 348-366.

5. Hobbs JE (2002) "Evolving supply chains in the nutraceutical and functional foods industry". Canadian Journal of Agricultural Economics 50(4): 559-568.

6. List GR (2004) Decreasing Trans and Saturated Fatty Acid Content in Food Oils, Food Technology 58(1): 1-8.

7. Lockie S, Lyons K, Lawrence G, Mummery K (2002) Eating 'Green': Motivations Behind Organic Food Consumption in Australia Sociologia Ruralis 42(1): 23-40.

8. Weaver RD, Rosa F, Vasciaveo M (2015) "Price Transmission: cointegration and asymmetries $52^{\text {th }}$ SIDEA Conference, Viterbo, Italy.

9. Rosa F, Weaver RD, Vasciaveo M (2015) "Structural Changes and Dairy Chain Efficiency in Italy". Journal Food System Dynamics 6(3): 191211.

\section{Your next submission with Juniper Publishers will reach you the below assets}

- Quality Editorial service

- Swift Peer Review

- Reprints availability

- E-prints Service

- Manuscript Podcast for convenient understanding

- Global attainment for your research

- Manuscript accessibility in different formats

( Pdf, E-pub, Full Text, Audio)

- Unceasing customer service

Track the below URL for one-step submission

https://juniperpublishers.com/online-submission.php 